\title{
ALGUNAS REFLEXIONES SOBRE LOS LENGUAJES DEL ARTE*
}

Fernando de Szyszlo

La generosidad de los miembros de la Academia de la Lengua, de su directiva y en especial de su Presidente, el Dr. Luis Jaime Cisneros, son los culpables de que yo aparezca, un poco tímidamente es verdad, ante ustedes. Como sé que no es una decisión que se toma a la ligera me cuesta trabajo atribuirla solamente a la vieja amistad y al largo camino que hemos recorrido ambos desde que nos conocimos, en casa de Francisco Moncloa, seguramente en 1946, cuando Luis Jaime regresó de Argentina. Debo también recordar que la única pieza que he publicado que pretendía ser de creación literaria, un breve cuento, apareció en 1947 en la Revista "Mar del 'Sur" que en esos años, Luis Jaime Cisneros dirigía con Aurelio Miró Quesada. Gracias también son debidas a Mario Vargas Llosa que ha aceptado ser quien me reciba en el seno de la Academia.

La única razón de peso que puede otorgar a una persona como yo un sitio entre tan destacado grupo de escritores peruanos es mi indeclinable amor a la literatura. Si más adelante en este texto afirmo que estoy con los que creen que en la historia del hombre el signo, la forma, el diseño precedió a la

* Leído en la ceremonia de incorporación, el 13 de noviembre de 1997. 
palabra en transmitir contenidos simbólicos, debo reconocer que en la historia consciente de este hombre que les habla, la palabra precedió a la imagen. No tengo ninguna memoria de haber, no digo pintado, de haber dibujado nada, ni haber tenido deseo de hacerlo, antes de los 17 años, terminada ya mi educación escolar con los jesuitas del Colegio de la Inmaculada en la Avenida Nicolás de Piérola, en el centro de Lima.

Pero tengo una memoria muy clara de los libros que he leído en mi adolescencia. De mis lecturas de infancia sólo recuerdo esa especie de enciclopedia que se llamaba "El Tesoro de la Juventud", aparte de ella quisiera poder olvidar que en mi infancia leí también novelas policiales de Sexton Blake e historias de Tarzán de Edgar Rice Burroughs. No recuerdo sin embargo haber leído libros para niños; "El Principito" todavía no había sido escrito y seguramente todavía en esa época Saint-Exupery hacía vuelos nocturnos de correo en biplanos por las pampas argentinas.

Felizmente a los catorce años tuve suficiente criterio como para prestarme de mi compañero de clase José Durand Flórez, unas maravillosas ediciones in-folio de Julio Verne ilustradas en el estilo de Gustave Doré. A través de Verne y de Alejandro Dumas se abrieron para mí las puertas de ese mundo fascinante y encantado que es la literatura. La literatura me ha alimentado y angustiado, me ha aterrado y ayudado cuando en la soledad necesitaba amigos. He vivido con ella varias vidas y compadezco a las personas que no hayan disfrutado de esas amistades. Como muchos latinoamericanos de mi generación debo a la revista argentina "Leoplán" mis primeras lecturas de novelistas rusos, Dostoyevski y Tolstoi fueron pasiones tempranas. Vino después Balzac y la novela realista francesa: Flaubert y Stendhal.

Luego llegó la experiencia inolvidable de "La Montaña Mágica", de la novela norteamericana, especialmente Faulkner y finalmente la lectura afiebrada de Marcel Proust, en la traducción que iniciara don Pedro Salinas y que terminara Mar- 
celo Menasché. Como la traducción estaba en proceso los libros en la edición de Santiago Rueda llegaban de Buenos Aires muy irregularmente y conocimos esa ansiedad que fue común en Francia en el siglo XIX, cuando los lectores esperaban los capítulos de las novelas de Balzac publicadas en folletín.

Después vinieron obras tan importantes como la prosa y la poesía de Jorge Luis Borges. En París en 1949 encontré a Octavio Paz: haberlo conocido pasará "por un raro privilegio" del que siempre fui consciente. Poco después leí maravillado "Pedro Páramo" de Rulfo y llegó entonces el gran deslumbramiento de "La Ciudad y Los Perros" y todas las inolvidables novelas de Mario Vargas Llosa que siguieron. Indudablemente que el éxito internacional de "La Ciudad y Los Perros" abrió las puertas para que lectores de todas partes del mundo descubrieran y pudieran entrar en contacto con todo un grupo de brillantes escritores latinoamericanos. A lo que vino entonces se llamó el "boom" y dentro de él aparecieron libros tan valiosos como "Cien Años de Soledad" de García Marquez y "Tres Tristes Tigres" de Cabrera Infante.

Simultáneamente realicé el descubrimiento de la poseía. La poesía me ha acompañado también toda la vida, pero aún más, ha estado presente en mi pintura.

Muchas veces la lectura o la relectura de un poema me ha provocado un clima, una atmósfera, un estado de ánimo que ha resultado en un cuadro. Si bien he leído poesía francesa desde muy jóven, en que comencé con Baudelaire, a quien luego siguieron Rimbaud, Verlaine, Saint-John Perse, Paul Valery y los surrealistas; es lógicamente, la poesía en mi lengua la que ha estado más cerca de mí. San Juan de la Cruz, Fray Luis, Quevedo y Góngora son lecturas que nadie puede haber hecho sin quedar permanentemente afectado. Algunos de esos poemas, o fragmentos de ellos, los tengo hasta hoy impresos en mi memoria. De la poesía contemporánea en español son los latinoamericanos a los que más próximos he sentido,Vallejo y Neruda son dos poetas que he frecuentado toda mi vida, pero 
al lado de ellos están Octavio Paz, Westphalen, César Moro, Enrique Molina y la gente propiamente de mi generación como Jorge Eduardo Eielson, Javier Sologuren, Sebastián Salazar Bondy y Blanca Varela.

Esta vieja relación de un pintor con la literatura me hace pensar que puede tener sentido compartir con Uds. algunas reflexiones sobre los lenguajes del arte que me han perseguido desde siempre.

Desde la prehistoria hasta hoy el hombre ha conocido diferentes fortunas, sufrido muchos cambios, ha vivido épocas de fanatismos sangrientos, de intolerancias, de barbarie y de glorią, todas con el correr del tiempo se han convertido en épocas legendarias, en mitos.

Es díficil decidir si Aquiles es menos histórico que Homero, en todo caso es evidente que conocemos mejor a Ulises que a Homero o que a ninguno de sus contemporáneos, y que Dimitri Karamasov, Charles Swann y Julián Sorel forman parte del grupo de personas que hemos conocido profundamente, tanto o más que a algunos de nuestros más cercanos amigos.

A pesar de todos los cambios sufridos, de todos los avatares vividos hay un propósito, que en el corto tiempo que la naturaleza le ha acordado para vivir, un propósito en el que el hombre nunca ha cejado: testimoniar, protestar contra su condición mortal y si no derrotar a la muerte por lo menos tratar, ilusamente, de llegar a un acuerdo con las oscuras fuerzas que algunas veces llaman azar, otras destino, pero que ciegamente, irremediablemente, presiden su historia. La historia del arte no es otra cosa que el depósito de los testimonios de gentes que quisieron sacar de la avasalladora destrucción del tiempo testimonios que dieran fe de su paso, y que finalmente se convierten en el rostro mismo de los pueblos de donde vienen sus autores. ¿Qué es el arte egipcio sino el rostro eterno del pueblo de Egipto? ¿Cuál sería la imagen que tendríamos de los griegos si no hubieran existido Esquilo, Platón o Fidias? 
¿Qué idea tendríamos de Francia si no hubiéramos leído a Rimbaud, a Flaubert, a Stendhal, si no hubiéramos visto cuadros de Matisse? ¿Qué idea tendría el hombre de sí mismo si no hubieran vivido Juan Sebastián Bach o Shakespeare? ¿Cómo sería el idioma que hablamos si no hubieran nacido Cervantes y Quevedo? ¿Qué pintura haríamos los pintores si no hubieran nacido Velásquez y Picasso?

Alguna vez el astrónomo Carl Sagan dijo que uno de los pasos más importantes en el desarrollo del hombre fue el invento de la escritura. Nos habla Sagan de que los animales menos evolucionados nacen con un gran porcentaje de su información ya genéticamente impresa. Es poco lo que aprenden y lo que pueden aprender en el transcurso de vidas que tienden a ser muy cortas. Conforme ascendemos en la escala animal y las especies son más y más complejas, el porcentaje de la información recibida es cada vez menor y la madre se debe ocupar del recién nacido por más tiempo. En el hombre este tiempo de tutelaje es el de más larga duración. La información con que nacemos es mucho menor y todo, o casi todo, salvo las más elementales nociones de supervivencia y de defensa, nos debe ser enseñado. Pero de una manera o de otra, trátese de hombre o animal, inicialmente toda la información que tenían la llevaban con ellos, almacenada en sus cuerpos. La gran diferencia que produjo la escritura fue que el hombre pudo guardar información fuera de su cuerpo. Esto representó no solamente poderla transmitir, sino poderla acumular, poderla adicionar y bien entendido, compartir y aprovechar.

Antes de la escritura, sin embargo, se habían producido en las cuevas de Altamira (en España), y en las de Lascaux (en la Dordoña, en Francia) pinturas rupestres de una belleza notable, pero que tienen además una característica muy importante: estas obras muestran unas imágenes de un diseño muy desarrollado en un momento que el hombre, antes del desarrollo de la agricultura, era un antropoide recolector y cazador que vivía con la diaria ansiedad del sustento y que estaba lejos de alcanzar un lenguaje evolucionado. El crítico inglés Her- 
bert Read nos señala muy precisamente que el arte "nunca ha sido un intento de aprehender la realidad como un todo -eso está más allá de nuestra capacidad humana; no ha sido ni siquiera un esfuerzo por representar la totalidad de las apariencias, sino que más bien ha sido el reconocimiento fragmentario y la fijación paciente de lo significativo en la experiencia humana. La actividad artística podría por lo tanto describirse como una cristalización a partir del reino amorfo del sentimiento, de formas significativas o simbólicas Sobre la base de esta actividad se hace posible un 'discurso simbólico', y surgen la religión, la filosofía y la ciencia como modos del pensamiento".

Si puede ser cierto que nuestro lenguaje debe ser una evolución de la comunicación elemental de los animales, el lenguaje humano hace muchos milenios que es fundamentalmente distinto. Los especialistas coinciden en que inicialmente los lenguajes primitivos son mágicos y míticos.

Aún para un profano es evidente que nuestro lenguaje es una consecuencia de la evolución de las manifestaciones de los animales que por medio de gritos mostraban sus intenciones de comunicar cosas experimentadas individualmente. Esos gritos que casi solamente describen emociones (dolor, deseo de intimidad, terror, celo, exaltación, etc.), que nunca alcanzan a cumplir las funciones simbólicas o representativas que tienen las palabras, pero que son, sin embargo, medios de comunicación y tienen un significado por elemental que éste sea.

Dentro de este conjunto de maneras de comunicarse caben igualmente, aún en el reino animal, las expresiones faciales que pueden acompañar y acentuar el significado de los gritos. Cuando llegamos a las sociedades humanas, aún las más primitivas, los gestos y, sobre todo, los movimientos corporales adquieren progresivamente un valor expresivo individual que parece rápidamente derivar hacia otro de los lenguajes del arte: la danza. La danza comienza por ser un lenguaje corporal, del que existen numerosos ejemplos en el mundo animal 
(pensemos en los ritos de los animales en celo, etc.), pero que en el hombre, casi naturalmente se una con la música, para constituir uno de las más antiguas formas que toman los ritos religiosos y una de las manifestaciones que están presentes en todas las culturas sin importar su grado de desarrollo y que se producen por muy distintas razones: hay danzas para el combate, para propiciar la lluvia, para cumplir con los ritos de la pubertad, etc.

Ciertas civilizaciones prohiben las representaciones de imágenes religiosas porque piensan que lo sagrado no se debe intentar siquiera representarlo visualmente. En ciertas sociedades primitivas la gente evita ser fotografiada porque al producirse el retrato, creen que se les roba parte del alma. Todas estas conductas revelan en el hombre una antigua relación mágica entre la realidad y su imagen. Podemos pensar que al comienzo de la historia, en el mundo alrededor del hombre primitivo, las palabras con que él designó ese mundo constituyeron, a su manera, conjuros mágicos, signos para poblar el entorno, para tornar benévolas presencias que aparecían hostiles.

Frente a una realidad desconocida, nueva, lo primero que hizo el hombre fue darle un nombre a las cosas para que pudiéndolas nombrar, pudiera otorgarles identidad, existencia. Hasta el final de la Edad Media, todas las cosas que tuvieran un uso importante tenían, además, un nombre individual, desde la espada del Rey Arturo, hasta el caballo del Cid.

El filósofo francés Merleau-Ponty nos hizo notar que "el pensamiento no existe fuera del mundo, ni fuera de las palabras" y también que "el lazo de la palabra a su sentido vivo no es un lazo exterior de asociación: el sentido habita la palabra”.

El hecho que ignoremos, que no podamos nombrar con precisión cosas que pertenecen a una realidad oscura, oculta, desconocida, no impide que las experimentemos profundamente, aún si lo hacemos en una forma imprecisa e inefable. Estas 
realidades pertenecen a un mundo que solamente es expresable a través del arte, mediante un lenguaje que trasciende al propio lenguaje utilizado, sea palabras, formas o sonidos según se use el mundo de la poesía, de las artes visuales o de la música.

A través de ese lenguaje alcanzamos una realidad "otra", en que palabras o formas o sonidos adquieren en cada caso un significado diferente. Nacido, éste nuevo sentido, de su confrontación con otras palabras o formas o sonidos, cuyos significados al chocar unos con otros producen uno tercero sin relación directa con los que lo conformaron.

Igual que en el lenguaje oral en el que se pueden distinguir las palabras usadas en el lenguaje de la poesía y las usadas para el diálogo coloquial, la información o la explicación, todo lo que Mallarmé llamaba el "reportage"; en pintura se puede usar la descripción del mundo a nuestro alrededor, también en una manera totalmente descriptiva (el rostro de una persona, un momento de una batalla, un paisaje, etc.), pere igualmente como en la poesía pueden tener un significado que no es necesariamente el del tema representado sino que navega, oscuramente, debajo de la piel del cuadro, no importa si éste se sirve o no de la representación de la naturaleza. (Un paisaje de Rembrandt puede ser más dramático, más trágico, que el Martirio de San Sebastián de Sodoma; sin que esto implique un juicio de valor, pero que puede hacernos ver que el lenguaje de la pintura no está vinculado necesariamente con los temas que usa. La famosa frase de Pascal "Vanidad de la pintura que quiere hacernos admirar cosas cuyos modelos no nos interesan", representa toda una estética: la de una época que creía que la calidad de la pintura estaba relacionada con la importancia de los temas que representaba. Es evidente que Zurbarán no admiraba los cacharros, ni Cezanne admiraba las manzanas, admiraban a través de ellos lo que el juego de la luz y la sombra les transmitía y que querían fijar y a su vez transmitir). 
Personalmente comparto la explicación de Jung, de que el lenguaje del arte nace en una zona muy oscura del inconsciente y acepto también que ese inconsciente individual tiene vínculos, denominadores comunes con el inconsciente colectivo y que es por ese puente que el artista se comunica con su lector, con su espectador.

La obra de arte, aún tratándose de la narración más realista, es percibida por cada una de las personas que la confronta de una manera diferente; cada lector, cada espectador es al mismo tiempo un cómplice, él añade al experimentar la obra todo su mundo propio de asociaciones, y de memorias. La obra original está sujeta al universo espiritual de otra persona y resulta en un todo particular que es la suma de la obra más el mundo del que la experimenta ("Todo lector es un lector de sí mismo" decía Proust). Creo por ello que una obra de arte es diferente para cada lector, para cada espectador. Para cada generación el mismo libro, el mismo cuadro, es otro, diferente, aún para nosotros mismos el libro que leímos hace veinte años es otro libro cuando lo leemos hoy. Si a esto le añadimos que aún para su autor la obra terminada es inexplicable, que ni las circunstancias en que fue hecha, ni las intenciones que pudieran haberla originado bastan para esclarecerla; porque el proceso de su realización no es un proceso racional: Una obra de arte sólo puede ser experimentada, nunca puede ser comprendida.

La diferencia fundamental entre la poesía y la pintura es evidentemente el hecho que las palabras que usa el poeta son las mismas que usan el resto de los hombres para sus tratos por diferentes que sean (lenguaje diario, científico, profesional, etc.).

Las formas y los colores con los que se expresa el pintor se parecen más a los sonidos y los ritmos con que se expresa un músico: por sí solos ni colores ni sonidos quieren decir nada, cobran vida en relación al contexto que los envuelve. Para citar a Octavio Paz: "Las artes plásticas y sonoras parten de la 
no-significación; el poema, organismo anfibio, de la palabra, ser significante". Esta diferencia aparentemente enorme entre los elementos de la poesía y los elementos de las otras artes es la realidad menos importante que lo que las une y relaciona: el hecho de constituir lenguajes, sistemas de expresión y comunicación a un nivel tan profundo que hace que una explicación racional de su significado es prácticamente imposible, las más de las veces: inútil.

Hay también otra diferencia por establecer: la diferencia entre la poesía y la prosa. La poesía usa las palabras como los pintores usan los colores, cada uno de éstos es definitivamente modificado por el color que tiene al costado y podemos, por ejemplo, percibir un color naranja como rojo si el color que está a su lado es amarillo y podemos percibirlo como amarillo si el color que le está vecino es rojo. Los significados en un poema son producto de la interacción de unas palabras con otras. En la prosa el significado está esencialmente vinculado a la narración, pero esa narración, creo, no es el producto de un tema por narrar al cual luego se le da una forma escrita, sino que esa historia viene también indisolublemente unida con las palabras que la transmiten.

En el caso de la pintura, que desde el renacimiento hasta mediados del siglo XIX usó de la descripción minuciosa del mundo para expresarse, este hecho consistió en la habilidad de descubrir un elemento más, una herramienta nueva, añadida a las que ya disponía el pintor para expresarse: el poder llevar con admirables capacidades técnicas la representación del mundo de la realidad. No quiere esto decir, obviamente, que antes del renacimiento, la pintura hubiera sido abstracta sino que su calidad no se vinculaba a la minuciosa descripción de la naturaleza.

La pintura usaba la alusión a la naturaleza como uno de los elementos de su lenguaje, de la misma manera como en música la Opera usa el argumento de la historia que narra como un elemento que participa positivamente en la obra. 
Pero en la alusión a la figura humana que hay en los tímpanos de las catedrales góticas por ejemplo, el artista no ha querido describir las figuras que esculpe sino que, a través de la representación de la figura, expresarse y expresar lo que el tema le inspira, sin preocuparse demasiado de que la imagen sea o no parecida a la realidad. De igual manera lo hicieron los artistas pre-colombinos o los artistas llamados "primitivos" de Africa o de Oceanía, para todos ellos la forma exterior de la obra no es sino la delgada piel que envuelve un contenido palpitante, es más esa forma, esa delgada piel, es el aspecto que toma, casi sin poder controlarlo el artista, el contenido que busca afanosamente dejar de ser una compulsión subjetiva y encontrar la manera de hacerse objetivo.

El milagro se produce cuando los materiales inertes, neutrales, de la naturaleza se convierten en obras de arte, es decir entran al mundo de las significaciones; entonces contemplamos cómo polvos de color molidos en un líquido adhesivo y aplicados con unas cerdas atadas a un trozo de madera, adquieren el poder de conmovernos: como igualmente sucede con las palabras que sacadas de su mundo coloquial terminan expresando mundos interiores insospechados que no figuraban en el significado inmediato de cada una de las palabras que componen el poema. (La famosa anécdota del pintor Degas con Mallarmé -que me permitirán repetir aquí- es una espléndida ilustración y un perfecto resumen del problema: Según cuenta la historia, Degas llega un día a casa de Mallarmé y le dice: "Stephan tengo una magnífica idea para un soneto". Mallarmé responde: "Estas perdido, los sonetos no se hacen con ideas sino con palabras...").

Es evidente que el arte del Siglo XX ha buscado incesantemente debajo de la piel de las palabras del poema o de las formas del cuadro, tratando de encontrar ese idioma que transcurre por debajo del significado corriente de las palabras o de la asociación directa de lo que representan las formas y que enfrentadas a las otras, palabras o formas, que las rodean, saltan como en un arco voltaico, sin una lógica coherente, car- 
gadas de significados diferentes y con una enorme y deslumbrante capacidad de comunicación. No se refería André Breton a otra cosa cuando hablaba de que "La poética está asentada sobre el choque de las palabras, su enfrentamiento inesperado. La novedad está no en los elementos sino en sus relaciones". De esta manera pues, el misterio de la poesía que puede lograr comunicar mundos interiores inexpresables en el lenguaje coloquial, estaría en parte dado porque las palabras en el poema no actúan simplemente en función de sus propios significados, sino que además este significado es modificado, corregido por el choque con las palabras que la acompañan, las que a su vez sufren la misma transformación.

- En el caso de la pintura, como en el de la música, lo significado es inmanente al significante, lo que equivaldría a decir que el contenido está apresado en la forma, en otras palabras el contenido está inmanente en la forma. Alguna vez Henri Focillon dijo: "El signo significa, la forma se significa". La pintura no tiene un significado, es un significado; su significado no es un atributo de su esencia, es su esencia.

Todo esto nos lleva a una conclusión inevitable, que Paz hacía notar en "El Arco y la Lira": "ser un gran pintor quiere decir ser un gran poeta: alguien que trasciende los límites de su lenguaje". El esplendor del renacimiento y las cumbres a las que entonces llegó la pintura, hizo que el significado de un cuadro estuviera mucho tiempo confinado al significado del tema que el cuadro representaba. Una famosa historia, creo que recogida por Vasari, cuenta que Miguel Angel al terminar la escultura que representaba a Moisés la habría golpeado con el cincel y le habría dicho: "Parla". Ahora nos damos cuenta que esta es una historia que describe la relación de cualquier pintor con su cuadro, no importa que éste sea geométrico, expresionista, abstracto o hiperrealista, lo que es importante para su autor es que hable, que comunique, porque ello quiere decir que ha empleado correctamente el lenguaje de la pintura y que con los elementos, "las palabras", que ella pone a su alcance ha logrado expresarse. 
José Ortega y Gasset tiene algunas afirmaciones muy interesantes en su magnífico libro sobre Velásquez a propósito del lenguaje y su significación en la literatura y la pintura. Dice Ortega que hay veces en las que producimos obras con una voluntad deliberada de que sea signo de nuestras intenciones. Se trata entonces formalmente de un aparato de significar. Una de las más importantes capacidades del hombre es esta creación de signos, esta actividad semántica.

El lenguaje, dice Ortega, está movido por la aspiración que su actividad comunicativa no necesite a su vez de interpretación. Como en la poesía el poeta dice algo, también lo hace el pintor en el cuadro y el músico en la melodía. La pintura sería un afán de comunicación, pero con procedimientos mudos. Se adopta el lenguaje de la pintura cuando se quiere decir algo que el lenguaje de las palabras no podría decir.

Según Ortega "la poesía", en rigor, no es un lenguaje. Usa de éste, como mero material, para trascenderlo y se propone lo que el lenguaje 'sensu strictu' no puede decir. Empieza la poesía donde la eficacia del habla termina". Y añade más adelante que el cuadro con su silencio podrá, en cambio, dispararse en la sugestión de inefabilidades y que finalmente el cuadro existe como un conjunto de signos donde quedan perpetuadas intenciones. Hay pues, de acuerdo a Ortega, una constitutiva contradicción en la pintura entre lo patente que son sus signos y lo recóndito que es su sentido; vivimos frente a la pintura en una constante faena de interpretación, en suma que el cuadro nos está siempre haciendo señas. Pero nuestra reacción tiene que ser arrancarlo de las indecisas regiones en que suele flotar la obra de arte y tomarlo como lo que auténticamente es: una cristalización en que quedó fijada como cosa, un trozo de la vida de un hombre. Termina su meditación sobre este tema afirmando que "todo decir es deficiente", porque nunca logramos decir plenamente lo que nos proponemos decir y dice también que, al mismo tiempo, "todo decir es exuberante", porque nuestro decir manifiesta, implica siempre muchas cosas que se 
subdicen, y que son más de las que nos proponemos comunicar e incluso no pocas que queremos silenciar.

La idea del artista, como la entendemos ahora, es una idea bastante reciente. Los hombres del pasado, los que pintaron en la oscuridad de las cuevas las imágenes de los animales que cazaban, de los que dependían para su sustento y que mágicamente querían fijar en las informes superficies de sus guaridas; los hombres que impusieron a la plana superficie del desierto egipcio los intachables poliedros de piedra, o los que en las selvas de Guatemala o del Urubamba enfrentaron la naturaleza exuberante, enmarañada, amorfa, con la precisa geometría de una arquitectura imponente, los que hicieron todas esas maravillosas obras de arte, no eran artistas, el concepto no existía: no eran productores de obras de arte y la idea misma de arte tardaría mucho tiempo en definirse. Los autores de esas pirámides, o de esos templos 0 , más cerca, los que hicieron las máscaras Dogón en Africa o las barcas funerarias en Oceanía, no los hicieron con ningún propósito artístico. Eran productos en que participaban a la vez que lo mágico, lo" religioso y que eran el reflejo de la cosmovisión del grupo humano en donde eran realizados. Eran sobre todo intentos de responder a la realidad del mundo alrededor de ellos, una realidad incomprensible, amenazadora pero al mismo tiempo cargada de promesas y posibilidades.

No ha habido un grupo humano que no haya tratado de encontrar la manera de hacer más fáciles sus relaciones con las temibles fuerzas desconocidas que regían todos lo poderes cuya influencia era capital para su supervivencia, desde el clima, los cambios de las estaciones, hasta el concepto del tiempo, su fugacidad y la presencia de la muerte, también la esperanza de poder encontrar una forma de vivir más allá de la muerte. Lo que ahora llamamos un artista era entonces el creador de los objetos del culto y el inventor de las palabras con que el culto se realizaba. Era pues, en parte artesano, en parte sacerdote y en parte mago. Su objetivo era obtener la buena disposición de los dioses, con cosas que suponían los 
complacía y halagaba, como los sacrificios, las oraciones o las imágenes, tratando de conseguir "una conciliación de los poderes superiores al hombre y que se cree dirigen o controlan el curso de la naturaleza y de la vida humana" (Frazer). En esta función de puente entre la sociedad en donde vive y sus dioses, ese artista expresa, tenga o no conciencia de ello, los temores, los deseos de su grupo y cada vez que logró producir símbolos válidos para todos, fueran palabras, estatuas o pinturas, participó positivamente en la estabilidad emocional de su pueblo. La obra del artista, para Jung, cubre las necesidades psíquicas de la sociedad en donde vive, y de esta manera, sea consciente o no de ese hecho el artista es más que su propio destino, al darle forma trae el lenguaje del presente los viejos enigmas y las viejas angustias que nacieron con la especie. La obra de arte, sin embargo, nunca trae una moraleja, ni se pretende la verdad. Crece como una planta, como un árbol, no se explica ni es explicable, queda a nosotros encontrarla. "Ella transforma -dice Jung- nuestro destino personal en el destino de la humanidad y evoca en nosotros todas esas fuerzas benéficas que incesantemente y desde siempre han permitido a los hombres encontrar refugio de todo peligro y sobrevivir la más interminable noche".

Llegamos así a la noción de lo sagrado siempre tan presente cuando se habla de arte. Mauss decía que entendemos "lo sagrado bajo la forma de lo separado, lo prohibido" y si la evolución del arte a partir del siglo XIX, que es también la época en que Nietzsche se atreve a proclamar la muerte de Dios, se separa cada vez más del mundo religioso al que había estado desde el principio vinculado, siempre conserva ese vínculo secreto con lo sagrado, lo "sagrado laico", lo llamaría André Breton, André Malraux en "Las voces del silencio" confiesa que "el vocabulario religioso es aquí irritante, pero no hay otro", refiriéndose al arte añade: "no es una religión pero es una fe. No es lo sagrado pero es la negación del mundo impuro". 
El hombre siempre ha tratado por diferentes caminos de conjurar, de suscitar la presencia de lo que oscuramente -y a falta de mejor palabra- califica como "sagrado" y el arte ha sido siempre la herramienta o el puente para realizar esta búsqueda: con oraciones, blasfemias, imprecaciones, poemas o visualmente con estatuas, pinturas, espacios cerrados, cuevas, altares o también con sonidos, ritmos, y cánticos dentro del mundo de lo que llamamos música.

Llamaríamos sagrado entonces a todo lo que roza esa imagen primordial o arquetipo, de que habla Jung, imagen primordial que bien sea una presencia secreta, un ser humano $o$ un proceso, reaparece constantemente en el curso de la historia siempre que la fantasía se ha podido expresar con absoluta libertad. Vendría a ser como el residuo de incontables experiencias del mismo tipo de nuestros ancestros, oscuramente enterradas en lo más profundo de nuestras conciencias. El dramaturgo Gerhard Hauptmann decía que la poesía evoca con palabras, la palabra primordial, la primera, la original; que equivaldría a la frase de Breton refiriéndose a la pintura: "el ojo existe en estado salvaje".

Mucho de esto tiene el ambiguo sonido del lenguaje esotérico del que siempre he desconfiado pero con qué palabras precisar algo que no podemos atrapar con las herramientas de nuestro lenguaje y que sin embargo estamos todo el tiempo conscientes de que detrás del sentido lato de las palabras, de las formas, de los sonidos de los espacios cerrados y abiertos, tenemos permanentemente la sensación que esa significación inmediata no es todo el contenido y que por debajo del significado directo de ese verso, de la emoción que nos despierta ese cuadro, brota un significado "otro", como si el arte provocara en nuestro interior resonancias y ecos de cosas que nunca fuimos conscientes de que estuvieran ahí. Malraux no se equivocaba cuando decía que uno de los significados de la palabra arte es "dar conciencia a los hombres de la grandeza que hay en ellos, pero que ignoran". 
Es evidente también que al hacer ese papel de intermediario entre su sociedad y el mundo exterior que lo rodea, que a veces siente que lo amenaza y a veces que lo exalta, no importa si es consciente de ello o no, el artista se convierte en un "hombre colectivo" y en este sentido es un instrumento por medio del cual su circunstancia, su grupo humano y su época se expresan. Esa compulsión por crear, por expresarse, esa urgencia parece estar marcada por una energía que viniera desde atrás de nosotros mismos.

Encontrar un lenguaje a través del cual esas sensaciones puedan salir, hacerse objetivas, pasar de ser solamente una idea, un sentimiento, una extraña ansiedad, para convertirse en una cosa física, unas palabras escritas, una línea, un ritmo. Traspasar el ámbito de la experiencia individual y poder llegar al mundo de los otros. Haber encontrado el lenguaje apropiado $\mathrm{y}$, si es el resultado es una obra de arte, haberlo trascendido.

Es difícil decir en qué momento es que participa la vocación artística, si en el momento que el artista siente la compulsión incontenible de expresarse o cuando obedeciendo a esa urgencia escoge una manera de hacerlo, uno de los lenguajes del arte. Pero lo que me parece evidente es que el sitio en donde nacen todos estos lenguajes es el mismo y que solamente es el aspecto, el rostro, con que aparecen ante nosotros el que varía de uno a otro, de palabras a formas, a sonidos; ese sitio que creo que está en la parte más profunda del propio artista, está también, como lo dice Paul Klee, "en las entrañas de la naturaleza, en la fuente de la creación donde la llave secreta de todo se halla guardada".

Hay sin duda una conexión simbólica entre el artista y el mundo a su alrededor. Ser artista vendría a ser un intento de oponer a ese mundo que nos rodea, oponerle palabras, objetos, sonidos que testimonien que a pesar de todo la angustia, la gloria, la exaltación y la desesperanza que el mero hecho de vivir representa, queremos producir, sin embargo, obras que den fe de la interminable batalla. 
Es interesante observar cómo al testimoniar contra la condición humana, contra la muerte, su protesta cesa de ser individual y cuando es realmente una obra de arte, el paso del tiempo borra cada vez más sus perfiles individuales y aparece cada vez más como el producto de una época y de una sociedad. Creo que ser anónimo es el destino inevitable y al mismo tiempo el más alto que alcanza una forma artística, no tener autor determinado sino emerger de la historia y del pasado como emergen una catedral gótica, una pirámide o una piedra de Chavín; o también como esos nombres, como Homero, Shakespeare, Bach o Leonardo que ya no esconden detrás de la palabra que los designa a un ser humano sino a un mundo. 